\title{
ENFERMAGEM: UMA INTENÇÃO, UMA OPÇÃO, UMA PRÁTICA NO TEMPO DE NOSSAS VIDAS*
}

\section{Cilene Aparecida Costardi Ide**}

Neste momento, vocês, formalmente, passam a constituir um grupo que inicia, na Escola de Enfermagem da Universidade de São Paulo, a caminhada rumo à profissionalização. Agora, o principal está feito c pelo jogo da consciência vocês poderão ou não transformar $\mathrm{cm}$ prática o que até cntão era um convite, uma intenção, uma possibilidade.

As opções trazem junto com elas um universo de paixões, um mundo exclusivo de experiências a serem vivenciadas no tempo de suas vidas. Agora, acima e a partir das individualidades vocês, como grupo, refletirão uma história ao mesmo tempo real c imaginária. A amplitude de possibilidades dessa vivência, a intensidade e a qualidade dessa interação, a identidade que este grupo imprimirá às suas percepções, apreciaçōes e ações serão reconhecidas em hábitos de fazer e de pensar que se desdobra rão em consequências ainda desconhecidas. Na busca de sentido, é necessário analisar algumas cxperiências que serão, a partir de agora, compartilhadas por nós c que, por valcrem, continuam a exigir clareza.

A primeira experiência a merecer destaque diz respeito à opção por vocês assumida. Nossa interrogação sobre tal opção tem a ver com a origem dessa escolha profissional que convive com um pensamento permeado por concepçōes que idealizam um futuro a ser construído ou evitado, mas que já existe no presente de uma prática que ainda não lhes pertence. Assim, rejeitá-la a priori pressupõe desconsiderar uma demanda psíquica que trouxe cada um de vocês até aqui. Por isso, não se iludam. Ninguém caminha rumo a uma profissão absolutamente contrária à sua essência. Portanto, aos indecisos vale o desafio de aprofundar tal questionamento. É provávcl que a opção pela Enfermagem tenha um sentido que a ultrapasse c que ainda permanece desconhecido, exigindo de vocês clareza como condição indispensável ao desenvolvimento pessoal e profissional.

Por outro lado, a sensação de consonância a priori com uma profissão ainda não vivenciada e, além disso, plena de simbolismos, também merece questionamento, uma vez que evoca um sentido vocacional sempre distorcido. E possível que essa postura conviva com uma determinação social, religiosa, econômica ou com uma mistura peculiar de todas clas c que, não sendo assim

Aula proferida no dia 1/3/93, no Auditório Maria Rosa Souza Pinheiro da EEUSP.

** Doutora do Departamento de Enfermagem Médico-Cirúrgica, Presidente da Comissāo de Graduação da EEUSP. 
comprecndida, acabe exercendo uma pressão inconsciente sobre vocês, gerando pertinência em vez de opção e crescimento. Assim, àqueles que já se identificam com a Enfermagem, vale o desafio de prosseguir com os olhos suficientemente abertos para eleger e consolidar a própria maneira de ser c de vivenciar a profissāo, expressando uma voz própria frente às determinações externas.

Em decorrência da opção emerge a segunda experiência a ser vivenciada por vocês, agora, como sujeitos do processo de ensino da Enfermagem. Processo que convive com situações peculiares que o diferenciam dos demais, relativizando a utilização das teorias pedagógicas vigentes como suporte teórico-metodológ ico adequado ao nosso contexto. Nele, as questões cognitivas ganham um significado particular na medida em que a construção do nosso saber-fazer pressupõe a m anipulaçăo de pessoas como instrumento de ensino. Acima c além do apara to da sala de aula, da biblioteca, dos laboratórios, enfim, da adequação dos recursos didáticos, o desafio diz respeito a ousar promover cstratégias educacionais capazes de superar formas de aprendizado tecnicistas, pautadas numa concepção reducionista de corpo, passível de ser manipulado pela negação da sua condição humana. Aqui o inédito, o moderno, será promover estratégias pelas quais alunos adultos aprendam a cuidar de pessoas rea is e nāo de seres biologicamente catalogados, psicologicamente esvaziados, sociologicamente descaracterizados. Alunos reconhecidos como adultos e que, como tal; compartilhem das responsabilidades inerentes à profissão assumida. É próprio do ser humano quando não compreende o outro e não pode ignora-lo, exercer uma pressão, consciente ou não, sobre essa pessoa para transformá-la em algo possível de enquadramento gerando, com isso, regressão e distorção. Nesse contexto, o aprimoramento do cnsino da Enfermagem pressupōe identificar estratégias que viabilizem o aprendizado pela superação de formas de ação e de relacionamento pautadas no uso contínuo de mecanismos primitivos de defesa psíquica, úteis para negar a complexidade do conjunto dos nossos atos gerando, porém, consequências que a consciência ignora.

Como esse aprimoramento pressupōe maturidade e, portanto, a necessidade de sabermos o que somos e se somos cm relação a um outro ou a outros, essa noção torna-se também política, passando a enfocar a questão da origcm, das raízes, da identidade e especificidade da nossa profissão.

Na modernidade, o imaginário social transferiu para as instituições e práticas em saúde a mediação na busca da perenidade, condição sempre aspirada pelo homem e que se torna possibilidade quando a ciência passa a ocupar o lugar do divino na determinação do destino, da vida, da doença c da morte. Nesse contexto, a sociedade institucionalizou a Enfermagem como profissão responsável pcla disciplina desse universo de prática para iluminar, arcjar, projetar luz no que antes era escuridāo e masmorra, adequando o a mbiente hospitalar ao seu novo papel: recuperar vidas necessárias à susten- 
tação do Sistema. É nesse cenário que emergem nossos conflitos: a sociedade se apropria de demandas psíquicas dos que cuidavam, profissionalizando pessoas para responder, agora, a demandas sociais, diluindo expectativas por cuidar num novo e complexo cenário institucional. Se essa foi uma condição que atendeu às necessidades do seu tempo foi também uma mutação teratogênica na medida em que vem gerando profissionais inadaptados.

Assim, superar essa situação pressupõe propor um processo de ensino pautado num padrão de profissionalização cuja qualidade decorra da possibilidade de aproximar a demanda psíquica dos que buscam a prática do cuidar, da demanda social e institucional ${ }^{1}$. E todos vocês participarão, a partir de agora, desse movimento de aprimoramento curricular na tentativa de responder a uma urgência histórica: a reestruturação da prática do enfermeiro no contexto das práticas assistenciais cuja complexidade passa a exigir fundamentação, integração, flexibilidade e versatilidade nas intervençōes, nos padrões e ritmos das atividades. Um novo currículo capaz de promover uma competência pautada na habilidade com o domínio intelectual da açāo e um padrão de profissionalização ancorado em duas vertentes: o preparo sobre o cuidar e o preparo para a coodernação do cuidar, formando profissiona is aptos a reconhecer e compreender tanto as peculiaridades da sua atuação como também, a dinâmica dos princípios e práticas constitutivas desse desempenho, desmitificando a imagem de atividade anacrônica, inespecífica e alienada. ${ }^{1}$

O preparo do aluno sobre o cuidar deverá abranger conteúdos e estratégias que viabilizem a compreensão das condiçōes objetivas do exercício da profissão: a sua determinação; seu significado; as diferentes formas de organização e articulação desse processo de trabalho; as consequências ético-jurídicas dessa prática; os direitos e deveres de usuários e profissionais; as repercussōes desse trabalho na vida de seus agentes.

O preparo do aluno para a coodernaçāo do processo de cuidar, atividade aqui considerada como específica do enfermeiro no contexto da prática da Enfermagem, deverá agregar conhecimentos e habilidades necessárias ao desempenho da sua função peculiar, ou seja: sistematizar as atividades da equipe de enfermagem (esfera do cuidar) ; articular essas açōes àquelas desenvolvidas no âmbito da equipe multiprofissional (esfera do assistir-cuidar) ; mediar de forma consciente e competente as relações de poder inerentes ao seu processo de trabalho no âmbito de diferentes instituiçōes de saúde, modulando-as às necessidades e direitos da equipe e, consequentemente, dos usuários; promover condições para a consolidação da Enfermagem com estatuto de ciência que compartilha da esfera do curar a partir da sua especificidade: o processo de cuidar. Essa concepção de formação profissional pressupõe um processo de ensino capaz de promover o aprendizado a partir de referenciais teórico-metodológicos respaldados na esfera do cognitivo dimensão dos conhecimentos e habilidades específicas; na esfera do simbólico - dimensão voltada ao desenvolvimento da capacidade discente de apreensão, 
compreensão e intervençāo no contexto de crenças, atitudes e concepções inerentes ao processo saúde-doença. Processo de ensino respaldado, a inda, na esfera da política, espaço do desvendamento das relaçōes de poder interpessoal, intra e interinstitucional e na esfera da edụcação, referencial necessário para a adequação de intervenções voltadas à apreensão do capital simb6́lico e das representações sociais dos usuários enquanto subsídios para identificar demandas por saúde a partir das expectativas, necessidades e possibilidades de participação por eles manifestas. ${ }^{2}$

Finalizando, consideramos que a proposição dessa reorganização curricular pressupõe uma ruptura com o vigente. Poderemos ou não, alunos e professores, levá-la em consideração. Entretanto, devemos entendê-la como uma possibilidade de precisar e de evidenciar tanto alguns dos problemas em cena, como as perspectivas de superação. Na medida em que jogos da vontade não são feitos por pessoas ingênuas, do nosso querer e poder dependerão a crítica, o aprimoramento, a experimentação desta proposta. No cenário determinado e determinante das práticas de saúde, tentamos identificar o desafio bem como o espaço da nossa intencionalidade enquanto possibilidade de revolver conceitos, princípios c valores avançando, ou nāo, na consolidação do ensino e da prática dos enfermeiros no interior das práticas da Enfermagem.

\section{REFERENCIAS BIBLIOGRÁFICAS}

1. IDE, C.A.C. O uni verso do aluno ingressante: uma perspectiva de múl tiplos desafios. Rev.Esc Enf. USP, v. 26, n. 1, p. 3-7, mar. 1992.

2. IDE, C.A.C. ; CHA VES, E. Padrōes de profissionalização em Enfermagem. /A presentado no curso de atual ização. $O$ ensino do processo de cuidar do adul to: perspectivas para a questāo. Sāo Paulo, 1992./ 